Article

\title{
A Multi-Criteria Study of Decision-Making Proficiency in Student's Employability for Multidisciplinary Curriculums
}

\author{
Yueh-Min Huang ${ }^{1}$, Ming Yuan Hsieh ${ }^{2, *}$ and Muhammet Usak ${ }^{3}{ }^{\mathbb{C}}$ \\ 1 Department of Engineering Science, National Cheng Kung University, Tainan 70101, Taiwan; \\ huang@mail.ncku.edu.tw \\ 2 Department of International Business, National Taichung University of Education, Taichung 40306, Taiwan \\ 3 Kazan Federal University, Institute of Pedagogy and Psychology, 420008 Kazan, Russia; musaktr@gmail.com \\ * Correspondence: cpawisely@mail.ntcu.edu.tw; Tel.: +886-975-118-922
}

Received: 26 April 2020; Accepted: 26 May 2020; Published: 2 June 2020

\begin{abstract}
To effectively increase the employment rate of higher education graduates, higher education institutions are doing their best to provide the most high-quality technologized interdisciplinary curriculum, to educate professional expertise in decision-making and to fortify student employability. Therefore, after executing a series of evaluated measurements, there are four highly valuable and contributive conclusions and findings. First, judgeability was the most critical decision-making employability factor and was directly influenced by the self-efficacy (SE), self-control (SC) and self-regulation (SR) of the autonomy-learning performance of social learning theory (SLT). Second, the SE of autonomy-learning performance of SLT was positively impacted by the behavioral intention to use and actual system use of the technology acceptance model (TAM), and monitor, control and evaluate decision-making, select the best solutions, clarify the objectiveness to be achieved and search for possible solutions of rational decision-making model (RDMM). It is necessary for higher education graduates to possess judgeability to confidently deal with problem-solving issues by actually using diversified technological applications for clarifying, monitoring, controlling and evaluating the decision-making objectiveness, and to comprehensively search the possible solutions, in order to eventually induce the best solutions for the problem. Third, define and diagnose the issues or problems of the RDMM model affected by the self-control (SC) of autonomy-learning performance of the SLT theory, because higher education graduates have to possess justifiability to define and diagnose the problem-solving issues in-depth, by exercising the introspective self-correcting capacities cultivated from an interdisciplinary curriculum. Lastly, actual system use of the TAM indeed impacted the SR of the autonomy-learning performance of SLT, because higher education graduates have to assess, revise and justify their self-actions in thinking, motivation, feeling, cognition and behaviors, by self-observing and accumulating experience from an interdisciplinary curriculum.
\end{abstract}

Keywords: decision-making employability; technology acceptance model (TAM); social learning theory (STL); rational decision-making model (RDMM); multiple criteria decision making (MCDM)

\section{Introduction}

According to the annual report of the Taiwanese Directorate General of Budget, Accounting and Statistics under Executive Yuan, the statistical unemployed population with a college or university degree has increased to approximately 270,000 in 2019, up from 110,000 in 1998. The unemployed rate for people with a college or university degree has been around $5 \%$ for the past six years, which is about one percent higher than the overall unemployment rate in Taiwan, as shown in Table 1. 
Table 1. Unemployment Rate in Taiwan.

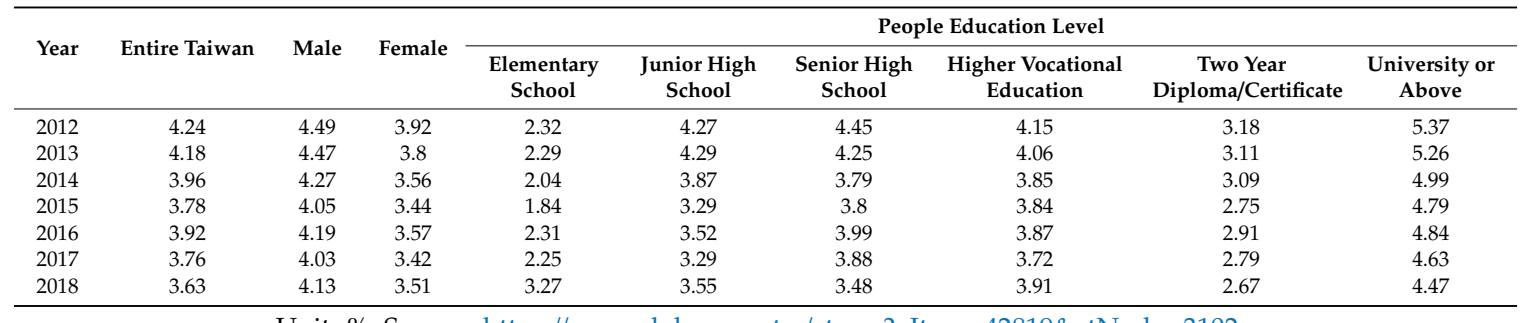

Unit: \%; Source: https://www.dgbas.gov.tw/ct.asp?xItem=42819\&ctNode=3102.

In order to improve the unemployment rate among higher education graduates, the Taiwanese Ministry of Education has instituted stimulating recruiting policies, such as hiring grants for companies to assist unemployed higher education graduates. Furthermore, the majority of Taiwanese corporations are skeptical of the professional value of a Taiwanese higher education diploma, due to the very high current acceptance rates at Taiwanese higher education institutions [1]. For this reason, the most of Taiwanese higher education organizations have started to strongly introduce various professional or technical certificates at universities of technology, business, research and education, to cultivate a student's professional capability after their graduation. Consequently, major global university rating organizations utilize graduation employment rate performance as the main assessed key performance indicator (KPI) in their evaluation of higher education institutions. The Ministry of Education in Taiwan has also incorporated graduation employment rates to be the main assessed KPIs in compensation regulation and policy for higher education institutions in Taiwan. This has led more higher education professors in Taiwan to begin to modulate their lecturing goal from academic "teaching-orientation and research-orientation" to empirical "employment-orientation" [2]. As a result, according to the 2019 comprehensive higher education graduate employment market survey by the Taiwanese professional magazine, Global Views Monthly, most companies did indeed consider that the most crucial unemployment problem for higher education graduates is not only that the majority of higher education graduates find it difficult to cultivate their effective employability [3] from the current disciplinary curriculum in a higher education institution, but that the bulk of Taiwanese enterprises also found it hard to recruit higher education graduates with outstanding decision-making proficiency, including (1) perspicacity: employees are supposed to have an excellent observed capability for detecting the most profitable niche before decision-making; (2) cognitivity: employees are supposed to possess an in-depth capability of investigating the business procedures in decision-making; (3) analyzability: employees are supposed to occupy a comprehensive capacity for evaluating the business circumstances of decision-making; (4) negotiability: employees are supposed to own an decisive capacity for striving for the best benefits of decision-making; and (5) justifiability: employees are supposed to have a decisive capacity to identify business accuracy and faithfulness beyond decision-making. Nevertheless, as higher education industry continues to develop, decision-making learning has gradually become a greater part of public life, when people make decisions related to the issues and problems with which they are confronted. Furthermore, thinking (individual cognition), action (people behavior) and result (society condition) are included in each decision-making process [4]. Furthermore, "thinking (individual cognition), action (people behavior) and result (society condition)" are included in each decision-making process in decision-making science [5]. In particular, based on the rapid development of goal-orientation in utilitarianism, the traditional decision-making lecturing often focuses on "result (society condition)" [6] without the consideration of thinking (individual cognition) and action (people behavior) in individual growth education cultivation. In particular, based on the rapid development of goal-orientation in utilitarianism, the traditional decision-making lecturing often focuses on "result (society condition)", without the consideration of thinking (people cognition) and action (people behavior) in individual growth education cultivation. The majority of current students started to be able to learn decisive competency only from a series of analytical courses in Taiwanese higher education institutions; particularly, the decisiveness is direct and necessary 
artifice in their employment anytime and anywhere after students graduated from higher education institutions. The most significant reason is "individual cognition forms personal behaviors; personal behaviors impacts individual cognition originality"; "personal behaviors constructs environmental development of entire society; environmental condition of entire society influences personal behaviors" and "individual cognition impacts environmental development of entire society; environmental condition of entire society forms from individual cognition". Specifically, with the rapid development of telecommunication and wireless technologies and swift expansive of 3C (computer, communication and consumer) electronic devices, more of current higher education curriculums have been involved into a series of the diversified technological applications, such as Officers software for individual lecturing and learning, internet websites for group literature and studying, Facebook and Line for social directing and emulating and so on, with the various 3C devices (Authors 2018). For that reason, in order to systematically embed decision-making employability in the core curriculums of current higher education institutions, "how to provide the most high-quality technologized interdisciplinary curriculum to educate professional expertise in decision-making to fortify student's employability" has been the most survived research issue. However, making comprehensive surveys [7-12] on decision-making proficiency in student's employability, there has been no research completed that has been able to synthetically and systematically assay and analyze the interdependence among the technological influence, learning performance and decision-making processes for supplying this academic gap and empirical issue.

Therefore, the interplays among "individual cognition, personal behaviors and social conditions" in the multidisciplinary decision-making relative courses have been the most three important analytical perspectives ("individual cognition, personal behaviors and social conditions") in this research. In order to solve this most brief academic research question, not only the technological influence of the technological acceptance model (TAM), but also the autonomic learning performance of social learning theory (SLT) [13], as well as the decision-making processes of the rational decision-making model (RDMM) into the three core analytical perspectives in Figure 1.

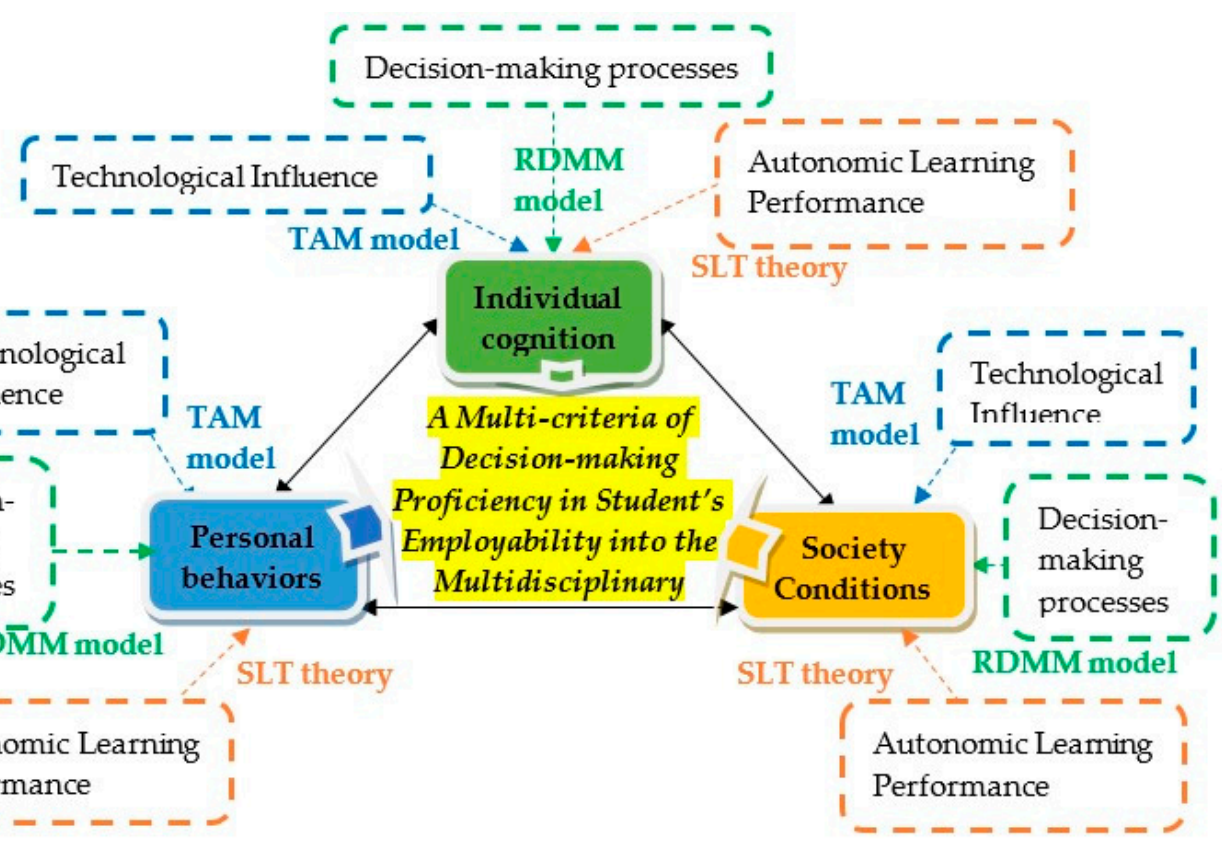

Figure 1. The three most important analytical perspectives.

In Figure 1, taking the connections of the technological influence of TAM model, autonomy-learning performance of SLT theory and decision-making processes of RDMM model into account, there are five briefest commonalities to be able to deeply assay and extensively evaluate the correlationships and interplays. These commonalities are (1) The reciprocal determinism has been definitely existed in 
three interactive-circle among individual cognitive, personal behaviors and society conditions which covers each individual cognitions, concepts and behaviors [14]. (2) The reinforcement effectiveness is interactive in three interactive-circles among individual cognitive, personal behaviors and society environment conceptual dimensions [14]. Intensively, the individual cognition motivation strengthens the personal behaviors implementation and the personal behaviors implementation enforces the individual cognition motivation; the personal behaviors implementation facilitates society condition development and the society condition development reinforces the personal behaviors implementation, as well as the society condition development, and enforces the individual cognition motivation, while the individual cognition motivation advances society condition development [15]. (3) The experienced observational autonomy-learning has been appearing in three interactive-circle among individual cognitive, personal behaviors and society environment conceptual dimensions [15]. The reason is that the personal behaviors will change in response to the transformation of the individual cognition; the social condition will be modified in accordance to the alteration of personal behaviors, as well as individual cognition, which will turn in connection to the re-construction of social conditions [15]. (4) The expectancy value is always previously created and justified in three interactive-circles among individual cognitive, personal behaviors and society conditions conceptual dimensions. The reason is that the personal behaviors are concrete accomplishments of individual cognition, and the society condition is a comprehensive achievement of the personal behaviors, as well as the fact that the individual cognitive is an abstract expression of the social condition. (5) The outcome is the final consequent expression of three interactive-circle among "individual cognition, personal behaviors and social conditions" [15]. The reason is that personal behaviors are hierarchically formed from the individual cognition, but the personal behaviors inversely affect individual cognition; the personal behaviors finally construct the society conditions; however, the society conditions conversely re-organize the personal behaviors and the social condition backward leads to individual cognition; nevertheless, individual cognition is an original source of social conditions.

Extraordinarily, in comprehensive analyses on individual cognition, not only the external variables of six assessed elements of technology-influence TAM model, but also the self-proactive (SP) of autonomy-learning performance of SLT theory [16], are both able to supply and promote (1) the defining and diagnosing the research issues or problems: separating symptoms from cause [17], (2) clarifying the objectives to be achieved: identifying criteria, of seven decisiveness processes of decision-making RDMM model, in order to boost [18], and (3) searching for all possible solutions: seeking all possible options for each issue or problem, of seven decisiveness processes of the decision-making RDMM model. Because the majority of decision-makers will use the diversified various electronic and electric devices (e.g., mobile phone, notebook, personal computer, etc.), to proactively collect the all relative information during confronting the issues or problems. In view of various assessments on personal behaviors, the perceived ease of use and the perceived usefulness of six assessed elements of technology-influence TAM model, as well as the self-organization (SO) [19] of five evaluated elements of autonomy-learning performance of SLT theory can facilitate and strengthen (4) comparing, evaluating and allocating the criteria-weights of each solution: evaluating all options for each issue or problem, of the seven decisiveness processes of decision-making RDMM model. In continuity, the attitude toward, and the behavioral intentions to, the use of six assessed elements of the technology-influence TAM model and the self-control (SC) [20] of autonomy-learning performance of SLT theory can accelerate and integrate to (5) select the best solutions: justifying why this choice and why not the others, of seven decisiveness processes of decision-making RDMM mod-el. In succession, the six assessed elements of technology influence TAM model and the self-efficacy (SE) [21] of autonomy-learning performance SLT theory are also able to assist and enforce (6) implement decision-making: executing steps and procedures of seven decisiveness processes of decision-making RDMM model [22]. Ultimately, the more advanced and sophisticated point is to probe into the interactive impacts among individual cognition, personal behaviors and social conditions after decision-making, the self-regulation (SR) [23] of autonomy-learning performance of SLT theory are necessary to be explicated for supplementary 
energizing the original expectation and intervention needed of seven decisiveness processes of the decision-making RDMM model.

Conclusively, according to Figure 1, in order to detect and assay the correlationships and interplays among individual cognition, personal behaviors and social conditions, the factor analysis ("FA") approach of quantitative analysis and the entropy method ("EM") and analytical network process ("ANP") of qualitative analysis of multiple criteria decision making ("MCDM") have been cross-employed step-by-step into a series of evaluated measurements for optimizing the results of questionnaires given to three surveyed groups: higher education students, professionals and experts in technological applications, self-learning performance, decision-making fields. The main reason is that the FA approach of quantitative analysis was firstly employed to systematically refine and categorize the entire commonalities of each evaluated criterion; the EM of qualitative analysis was secondly applied to comprehensively recognize the connected dependences among each evaluated criterion, as well as the fact that the ANP of qualitative analysis was further utilized to hieratically assess consistencies between each evaluated criterion through the consolidation of assessed consequences of the FA approach and EM method. Specifically, in sight of the ANP model essential concept, the ANP model was pioneered to be able to hierarchically appraise interplays among each evaluated attitude, criterion, sub-criterion and candidate (solution), by mean of the weight-questionnaires of professionals and experts with the higher research reliability, validity and representativeness [24-28], to completely construct the most effective technological determinants of the decision-making employability evaluated model ("TDDEEM") in order to comprehensively inducing a multidisciplinary multi-criteria of decision-making proficiency in student's employability.

\section{Literature Reviews}

\subsection{Multidisciplinary Research Theories and Models}

\subsubsection{Social Learning Theory (SLT) in Educational Disciplinary}

SLT theory was evolved from the SCT theory to observe and assay social learning from personal abstract cognitions and concepts to concrete behaviors, in order to discover the best avenues for advancing learning performance, because each person not only will refer the other's cognitions, concepts and behaviors from diversified observations and learning, but will also further strengthen the disadvantages of these distinctive observations to advance learning performance. Therefore, SLT was able to be utilized to construct a series of learning behavioral acquisition through various credible role models of the targeted behaviors. Besides, [14] delivered the concept of SE in the book, "SE: Toward a Unifying Theory of Behavioral Change". SE is that the individual can feel confidence in expressing a specific behavior or activity to achieve the success, without executing the traditional understanding study because "people's judgments of their capabilities to organize and execute courses of action required to attain designated types of performances" [14]. In continuity,

People are viewed as SO, SP, SR and SC rather than as reactive organisms shaped and shepherded by environmental forces or driven by concealed inner impulses. From this theoretical perspective, human functioning is viewed as the product of a dynamic interplay of personal, behavioral, and environmental influences. [15]

SC is that "Personal regulation of goal-directed behavior or performance; Provide opportunities for self-monitoring, goal setting, problem solving, and self-reward." [16] Conclusively, based on the essential definition, the five autonomy-learning performances of SLT theory were defined as assessed criteria and these are (1) SP: individuals are able to aggressively learn novel things in order to obtain up-to-date cognitive and experience [29]; (2) SE: individuals have sufficient belief to be able to confidently deal with and comfortably carry out things or issues, without the consideration of real own skills or techniques [29]; (3) SR: individuals are able to assess, revise and justify their self-actions in thinking, motivation, feeling, cognition and behaviors by mean of self-observation 
and experience-accumulation [30]; (4) SO: individuals are able to systematically form the concept and cognition based on their own thinking and experience and (5) SC: individuals have the capacity to practice introspection and willingness to study more about their essential purpose, feeling and essence [30].

\subsubsection{Rational Decision-Making Model (RDMM) in Decision-Making Disciplinary}

The broad definition of decision-making is "to make a decision or an option in the selected moment". In detail, the narrow definition of decision-making are able to be induced to three main understandings, and these are that (1) decision-making comprehends and identify issues or problems, set-up goal, analyze selection and solution for issues or problems, (2) decision-making is to choose the final solution for issues or problems from original decision-maker's options and (3) decision-making is to deal with a series of contingency without examples and regulations under any kind of uncertainties, which means that decision-makers have to confront the comprehensive decisive risk. Finally, operational decision, executed by each individual in the operations, is a sort of basic decision-making in connection with useful solutions for general issues or problems (e.g., studying schedule arrangement, product sale promotion, organization essential activities, corporate breakdown works, government key performance indicator settlement, etc.) with the breakdown activities for tactic and strategic decisions. In view of this subject, representativeness and complexity, decision-making were further classified into individual and group decisions. Individual decision is necessarily dependent on the perspicacity, identifiability, analyzability, negotiability and justifiability of the only one decision-maker. Furthermore, there are three kinds of circumstances in decision-making procedures [31], and these are (1) certain circumstance: there is only one issue or problem in order to easily find the decision-making goal with the apparent decisive benefits and specifically, decision-makers can form the unique effective solution from a couple of analytical schemes. Therefore, the maximum assessment of each decision-making scheme in mathematical calculations was applied in certain circumstances of decision-making analysis, (2) uncertain circumstance: there are a bulk of internal endogenous and external exogenous with uncertain things (e.g., possibility, frequency, percentage, proportion, etc.) in decision-making processes which results in decision-makers who are able to, with difficulty, integrate the only effective solution, and as a result, expectancy method which employs the computation and comparison of appeared possible of each potential scheme to measure feasibility and the level of risk-taking and decision-tree method, which utilizes the tree-sharp pattern to compute and analyze the appeared possibility and compared results of each potential schemes to induce the most suitable solution for issues or problems and (3) risky-taking circumstance: each main decision-maker, in risk-taking circumstances, is willing to take a risk in order to pursue the best solution for issue or problem according to the comparison of the deeper analytical processes (for example: breakdown process) and approaches (such as $5 \mathrm{~W} 1 \mathrm{H}$ approach: why, what, who, when, where and how). As a result, taking the decision-making steps into account, the essential four decision-making steps are first step: forming decision-making issues or problems, in order to identify decision-making main goal and potential schemes; second step: computing entire pros and cons possibility of all potential solution; third step: formulating the diversified feasible schemes, and fourth step: evaluating each feasible scheme in order to conclude the most suitable solutions for achieving the main decision-making goal. Significantly, the RDMM model was creatively formed in the current decision-making science based on these five innovative brilliant expositions, and then, there are a series of six executing steps. These seven executing steps [32,33] are (1) define and diagnose the issues or problems ("DDIP"); (2) clarify the objectiveness to be achieved ("COA"); (3) search for possible solutions ("SPS"); (4) compare, evaluate and allocate weights to the criteria of each solution ("CEAWCES"); (5) select the best solutions ("SBS"); (6) implement decision-making ("ID") and (7) monitor, control and evaluate decision-making ("MCED"), and these were all defined as the appraised sub-criteria. 


\subsubsection{Technology Acceptance Model (TAM) in Technological Disciplinary}

With reference to the diversified applications in various emerging technologies, such as telecommunication, wireless, internet, etc., more higher education students have been directly able to one-way surf the information, as well as to two-way inter-upload of individual news in the digital internet in the majority of classes. Following the rapid development of technological and digital teaching avenues in current Taiwanese higher education, not only have a bulk of Taiwanese higher education organizations experienced a multitudinous stress of concretely costs, but also a plurality of higher education participators have been enduring the numerous pressures of the technologized and digitized employment markets after graduation. Therefore, more educational researchers and government departments have realized that higher education institutions have to design and create a series of the multidisciplinary curriculums with the Internet technology ("IT") function services, with the lowest class expenditures. In view of current higher education participators' learning pedagogies, a majority of current higher education participators are used, to not only download professional knowledge and news, but also to upload individual experiences and opinions through various internet websites [34]. As concerns, this research employed the technological TAM model [35], to analyze higher-education participator's learning predilections and behaviors for detecting the dependences and interplays among technological influence, self-learning performance and decision-making processes, because these basic dimensions [36] were applied to evaluate technological user's "attitude toward using" and "behavioral intention", in order to recognize the user's "actual use behaviors", as shown in Figure 2.

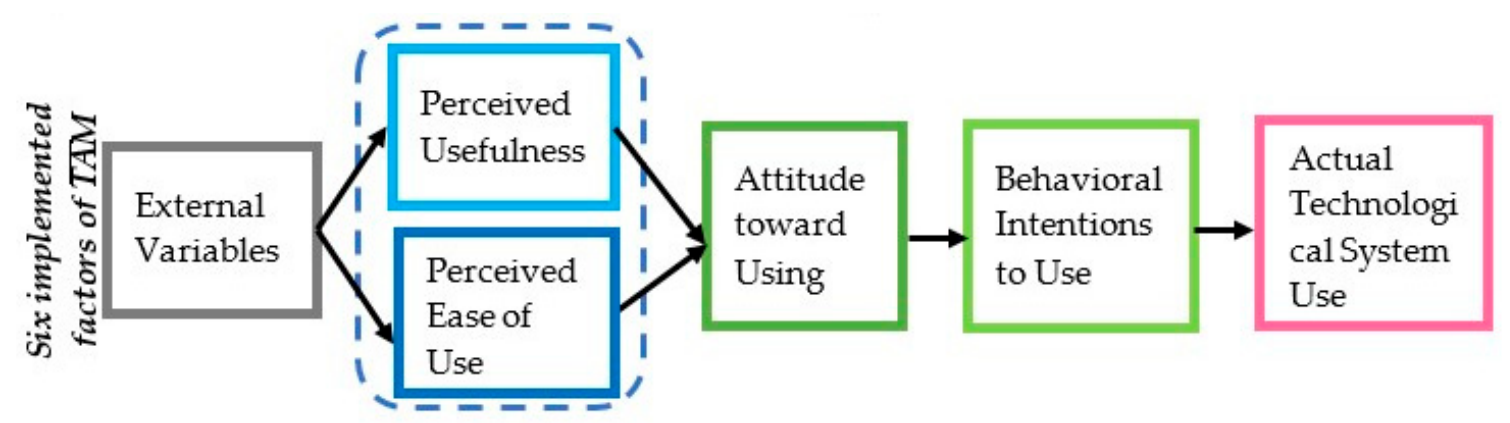

Figure 2. Technology acceptance model (TAM) model.

Inductively, the six implemented factors of TAM model [37-39] were applied as (1) external variable ("EV"): the technological users have to external considered inferences in operating technological system; (2) perceived usefulness ("PU"): the technological users subjectively deem useful cognition in the increment of performance during operating technological system; (3) perceived ease of use ("PEU"): the technological users have a kind of use-simplicity in operation technology; (4) attitude toward using ("AU"): the technological users have a bulk of negative and positive standpoints in order to affect their use-behaviors; (5) behavioral intention to use ("BIU"): the users' willing in operating technology and (6) actual system use ("ASU"): the users' actual operating action beyond a series of other implemented factors of TAM model. Extraordinarily, based on Figures 1 and 2, the six implemented factors of the TAM model and the five elements of SLT theory, as well as the seven executed decision-making steps of the RDMM model, are inductively and interactively integrated to form the main evaluated framework in Figure 3, in order to explore the most core decision-making employability determinants of multidisciplinary decisive education. 


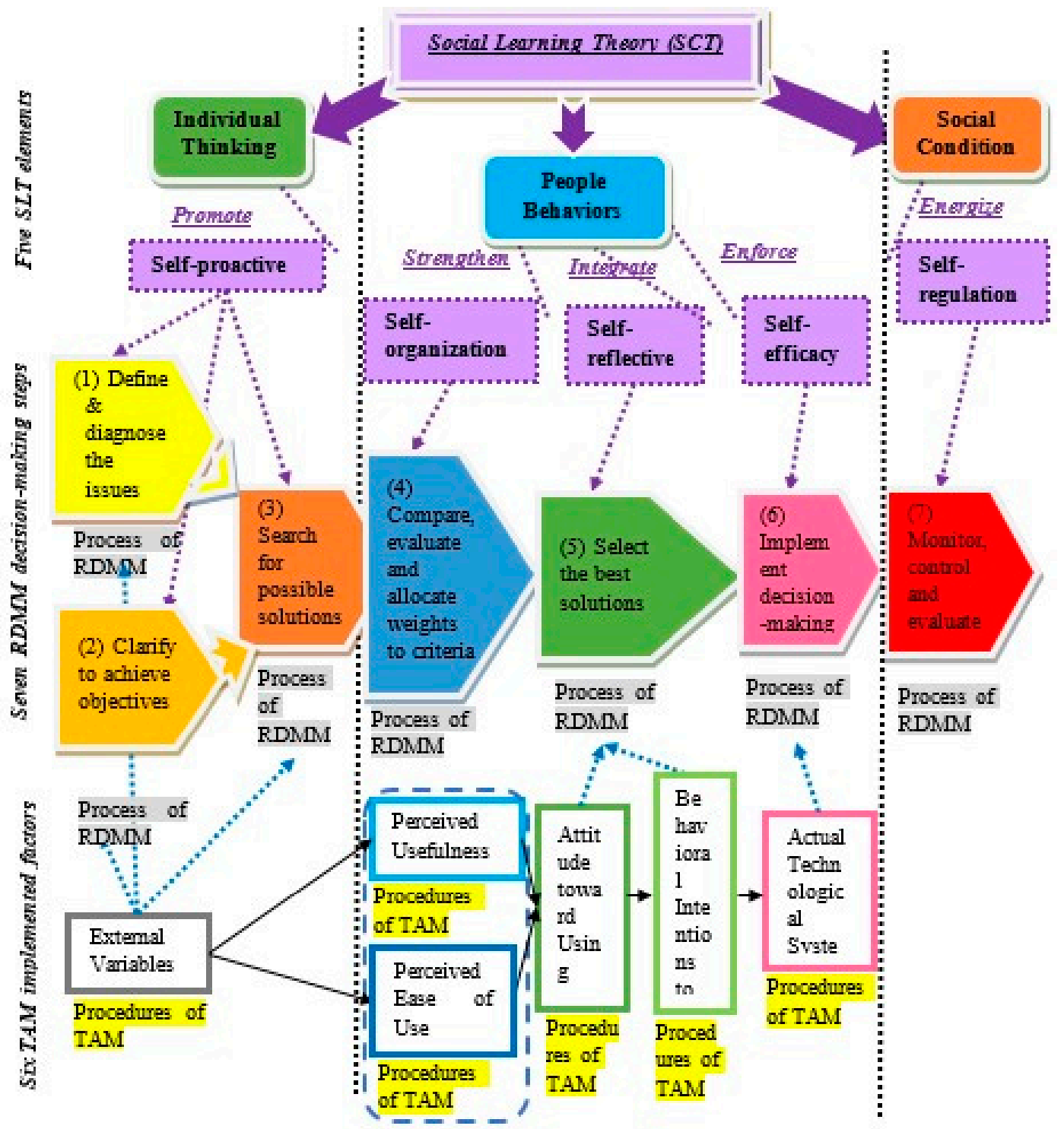

Figure 3. The main evaluated framework.

\subsection{Literature Review on Multiple Citeria Decion Making Methodology (MCDM)}

\subsubsection{Factor Approach (FA) of Quantitative Analysis}

In order to increase the research validity and raise the research representativeness, the FA was firstly utilized for assessments and categorization of questionnaires administered randomly to higher education students through a series of evaluations of correlation coefficient among each analytical variable (criteria). In analyzing theories, exploratory factor and confirmatory analyses in FA approach were the main assessed avenues in the FA approach, in order to perceive and testify segmentation and dimensionality of entire analytical factor variables in assessed scores. As for the statistic equation of FA, the linear equations were calculated as

$$
Y_{k}=w_{k 1} X_{1}+w_{k 2} X_{2}+\ldots+w_{k L} X_{L}
$$

s.t. $K$ numbers of common assessed factors are defined from the numbers of $L$ numbers and $M$ numbers are more than the numbers of K. Furthermore, the observed influenced factors were shown 
as $Y_{1}, Y_{2}, \ldots, Y_{L}$; the unobserved influenced factors are expressed as $X_{1}, X_{2}, \ldots, X_{L}$ and the factor loading constants are indicated as $X_{k L}$ [40].

\subsubsection{Entropy Method (EM) of Qualitative Analysis}

For comprehensively perceiving the interactive dependences between the seven decision-making processes of the decisive RDMM model, the autonomy-learning performance of educational SLT theory and the technological influence of the TAM model after executing the FA approach of quantitative analysis due to the original concept of EM method of qualitative analysis, EM method was pioneered to identify the correlationship compared measurements between the assessed criteria, through a series of pairwise compared matrices. Statistically, the "discrete probability connections" of the correlationship compared measurements were illustrated as $P_{1}, P_{2}, \ldots, P_{k}$ and furthermore, the Equations (2) and (3) of EM method were expressed as

$$
E\left(P_{1}, P_{2}, \ldots, P_{k}\right)=-\phi_{k} \sum_{i=1}^{k} p_{i} \operatorname{In}\left(P_{i}\right)
$$

s.t. $\phi_{k}=1 / I(k)$ described as the normal quantity and $0 \leq E\left(P_{1}, P_{2}, \ldots, P_{k}\right) \leq 1$. Particularly, the number of $E\left(P_{1}, P_{2}, \ldots, P_{k}\right)$ is directly related with each assessed criterion. Continuously, the expected dependences of the statistic duality equation of the conditional EM method were employed in the measures' entropy numbers $(H(Y / X))$ as

$$
\begin{gathered}
H(Y / X)=\sum_{x \in X} p(x) H(Y / X=x) \\
=-\sum_{x \in X} P(x) P(y I x) \log p(y I x) \\
=-\sum_{x \in X} \sum_{y \in Y} p(x, y) \log p(y I x) \\
=-\sum_{x \in X, y \in Y} p(x, y) \log p(y I x) \\
=-\sum_{x \in X, y \in Y} p(x, y) \log p(y I x) \\
\left.=-\sum_{x \in X, y \in Y} p(x, y) \log (p(x, y)) / p(x)\right) \\
\left.=\sum_{x \in X, y \in Y} p(x, y) \log (p(x)) / p(x, y)\right)
\end{gathered}
$$

\subsubsection{Analytical Network Process (ANP) Approach of Qualitative Analysis}

In order to increase the research reliability and accuracy, the hierarchical evaluated ANP model of qualitative analysis was cross-applied to classify the measured consequences of the FA approach of quantitative analysis. In sight of the ANP model development, the analytic hierarchy process ("AHP") model was the fountainhead of the ANP model. Originally, [41] pioneered the fundamental concepts of the AHP model for conducting more causality-oriented researches, through a series of hierarchical weighted measurements in the relationships pairwise matrices of four chief evaluated hierarchies: research topic, each evaluated pattern, assessable criterion and sub-criterion and potential candidate, in order to induce the most suitable solutions for the research questions. However, the AHP model was not able to directly deal with the "dependent relationships" in the relationships pairwise matrices of four chief evaluated hierarchies. Therefore, [42] developed the ANP model to create a more complex hierarchical analyses of the positive reciprocal and super pairwise matrix through the Delphi method and brainstorm avenues, to gather questionnaire data, in order to deeply assay the relationships pairwise matrices of four chief evaluated hierarchies in the various complicated research studies, as expressed in Figure 4. 


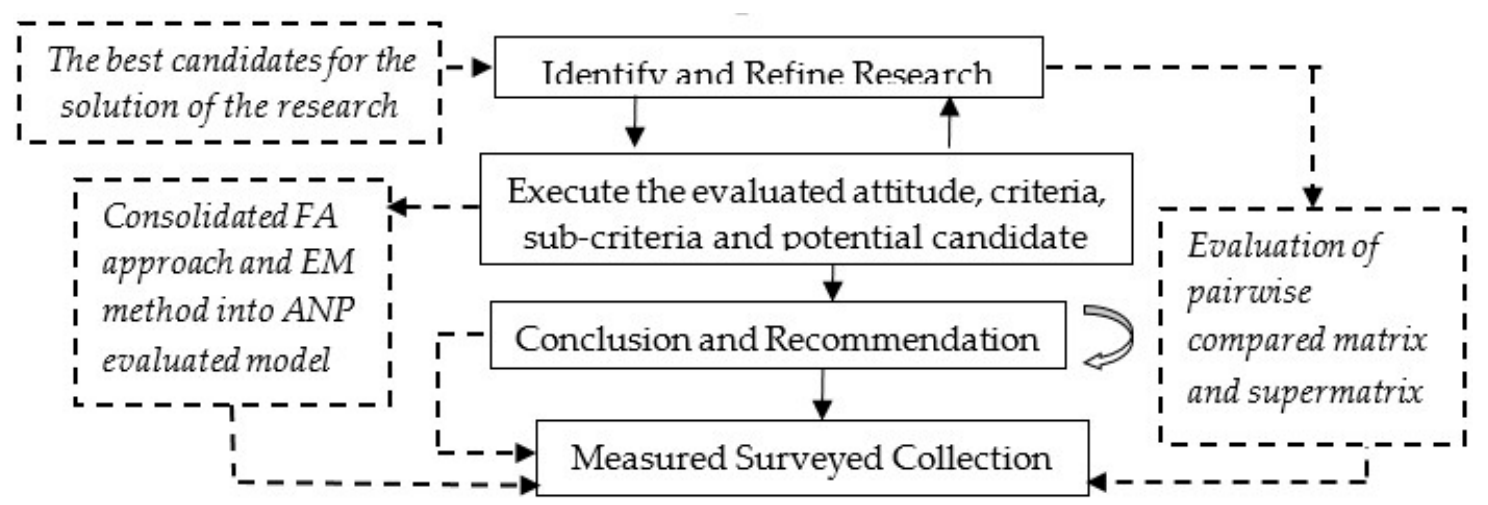

Figure 4. The main evaluated framework of analytical network process (ANP) model.

Sequentially, in view of the hierarchical ANP model measurements, once the pairwise comparisons are able to conduct the local priority vector $w$ (eigenvector) as the represented priority vector. Specifically, a two-stage algorithm was calculated in the initial equation:

$$
R w=\lambda_{\max } w ; w_{i}=\sum_{j=1}^{m}\left(R i j / \sum_{i=1}^{m} R i j\right) / \mathrm{m}
$$

Furthermore, in the assessable measurements of each pairwise comparison matrix of four chief evaluated hierarchies, the consistency of compared factors do deal with a series of assessed transitivity for fulfilling the representativeness of interviewed experts' opinions. The equation of consistency index ("C.I.") and consistency ratio ("C.R.") of the ANP model were described as

$$
\text { C.I. }=\left(\lambda_{\max }-n\right) /(n-1) ; \text { C.R. }=(\text { C.I. } / \text { R.I. })
$$

s.t. the random index ("R.I") acquired from the statistic random index figures.

In the original definition and assumptions of the ANP model, not only was the measured equation $\left(1 / n *\left(\sqrt[n]{\prod_{i=1}^{n} W_{i}}\right)\right)$ firstly applied to consolidate the equations numbers of C.I. and C.R., but the measured numbers of C.R. and C.I. also had to also be smaller than 0.1.

\section{Research Design}

\subsection{Research Processes}

According to Figures 1 and 3, the four main research steps were systematically designed for completing the entire research, and these steps are: (1) first procedure: defining research topic, question and goal: defining the research topic and target through the cross-employment of technological influence TAM model and autonomic learning performance SLT theory, as well as the decision-making processes of the RDMM from the three main analytical perspectives (individual cognition, personal behaviors and social conditions); (2) second procedure: Planning and constructing the evaluated model: the FA approach of the quantitative analysis and the EM method and ANP model of qualitative analyses were hierarchically cross-employed for constructing the most effective TDDEEM model; (3) third procedure: executing the entire evaluated measurements: the first apprised computations of the large-scale questionnaires of 100 random higher education students, the second assessed calculations of the empirical interviewed weight-questionnaires of 20 higher-education lecturers and the third evaluated measurements of the professional interviewed weight-questionnaires of 20 experts were synthetically implemented, as well as (4) the fourth procedure: concluding and analyzing the assayed consequences and measured results: the most valuable conclusion and contributive findings were directly induced from a complete analysis of the assayed consequences and measured 
results. Furthermore, according to the evaluated hierarchies of the original concept of ANP model, the research design framework of the most effective TDDEEM model was systematically constructed by the consolidation of the technological influence of the TAM, the autonomic learning performance of the SLT and the decision-making processes of the RDMM into the three core analytical perspectives (individual cognition, personal behaviors and social conditions), as described in Figure 5.

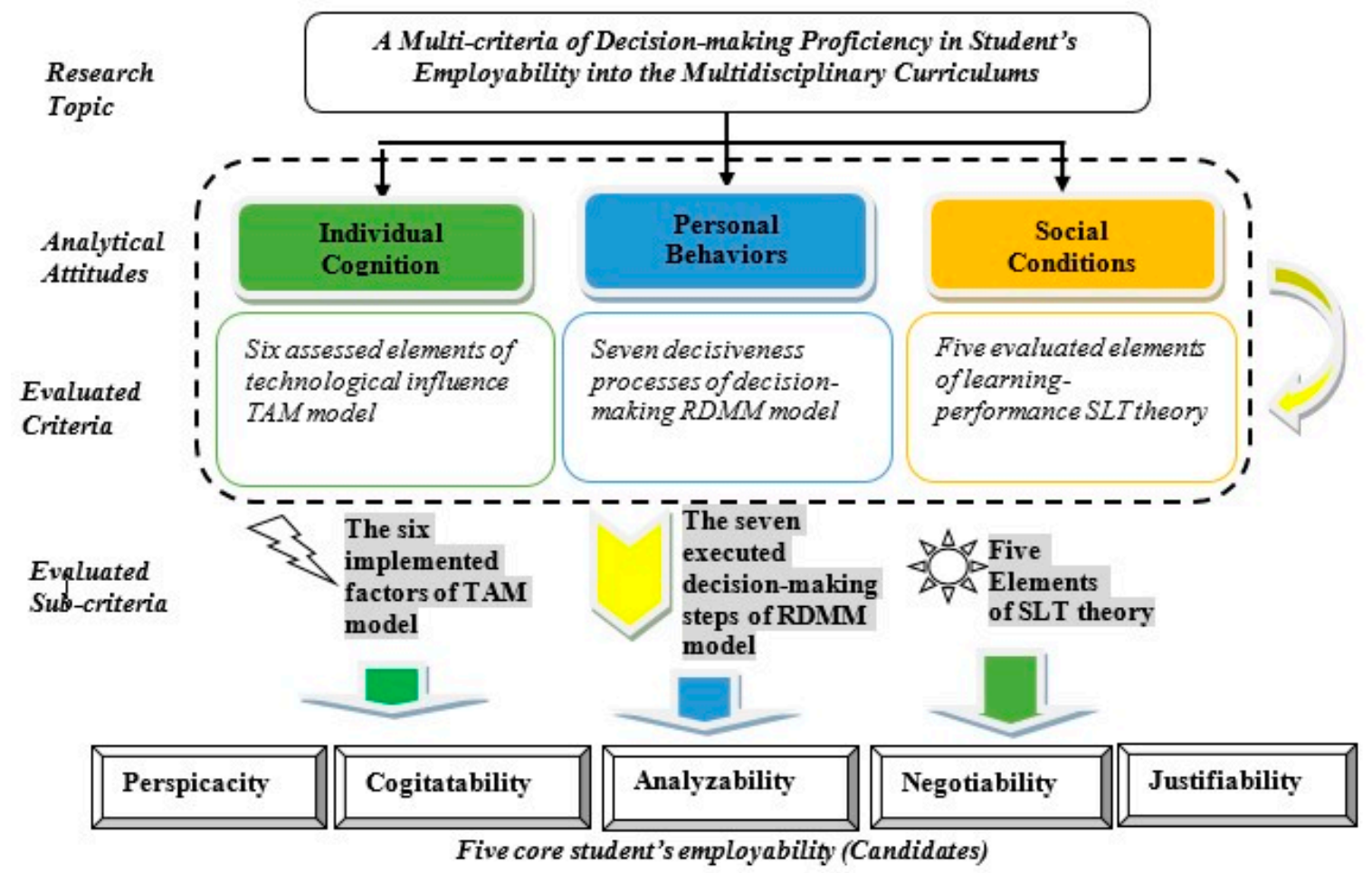

Figure 5. Research design framework.

\subsection{Surveyed Date}

In consideration of the representativeness and reliability, the valid 84 questionnaires of $\mathrm{m}$ 100 senior higher education students (over 20 years old) were collected in person from Chilung, Taipei, New Taipei, Taoyuan and Hsinchu cities (northern Taiwan areas), Miaoli county, Taichung city, Changhua, Nantou and Yunlin counties (middle Taiwan areas), Chiayi city and county, Tainan and Kaohsiung cities, Pingtung and Penghu counties (southern Taiwan areas) and Hualien and Taitung counties (eastern Taiwan areas), for the evaluated measurements of the FA approach. Specifically, there was a total of 40 professional experts interviewed for the hierarchical evaluation ANP model and systematical EM model of qualitative analyses for taking highest research accuracy and validity. The first 20 empirical higher education lecturers were surveyed in person for the weight questionnaire's calculations of the EM method of qualitative analysis, in order to increase research preciseness and actuality. Significantly, these 20 empirical lecturers all have over 5 years of teaching experience in multidisciplinary curriculums in Taiwanese higher education organizations. In succession, the other 20 professional experts were surveyed in person for the weight questionnaire's measurements for the ANP model of qualitative analysis, in order to hierarchically construct the most effective TDDEEM model. These 20 experts include the first 5 scholars who have over 5 years of experience in the decisive education relative research fields; the second 5, comprised of researchers who have over 5 years of experience in decision-making relative research fields, the next 5 , who are senior managers and have over 5 years of experience in human resources and the last 5, who are comprised of senior officers from related administration departments and have over 5 years of experience in the governmental labor market. 


\section{Research Measurements}

\subsection{FA Approach of Quantitative Analysis}

First, questionnaires were randomly sent to 100 higher education students from Taipei, Taichung, Kaohsiung and Hualien cities, of which ninety-four questionnaires were validly completed, which means, statistically, a questionnaire efficiency rate of $94 \%$. The descriptive statistic of these 94 valid completed questionnaires is described in Table 2.

Table 2. The descriptive statistic of the factor analysis (FA) approach.

\begin{tabular}{|c|c|c|c|c|}
\hline \multicolumn{2}{|c|}{ Gender } & \multirow{2}{*}{$\begin{array}{c}\text { Male: } 43(\mathbf{4 5 . 7 5 \% )} \\
\text { Central Taiwan: } \\
26(27.65 \%)\end{array}$} & \multicolumn{2}{|c|}{ Female: $51(54.25 \%)$} \\
\hline Geography: & $\begin{array}{l}\text { Northern Taiwan: } \\
\quad 29(30.85 \%)\end{array}$ & & $\begin{array}{l}\text { Southern Taiwan: } \\
24(25.23 \%)\end{array}$ & $\begin{array}{l}\text { Eastern Taiwan: } \\
15(15.95 \%)\end{array}$ \\
\hline $\begin{array}{l}\text { Use Internet } \\
\text { Hours/Per Day: }\end{array}$ & $\begin{array}{l}\text { Blow Two hours: } \\
\quad 36(46.8 \%)\end{array}$ & $\begin{array}{l}\text { Three hours: } \\
27(28.72 \%)\end{array}$ & $\begin{array}{l}\text { Four hours: } \\
18(19.14 \%)\end{array}$ & $\begin{array}{l}\text { Over four hours: } \\
\quad 5(5.34 \%)\end{array}$ \\
\hline \multicolumn{3}{|c|}{$\begin{array}{l}\text { Will you have experience on taking technological disciplinary } \\
\text { courses before? }\end{array}$} & Yes: 51 (54.25\%) & No: 43 (45.75\%) \\
\hline \multicolumn{3}{|c|}{$\begin{array}{l}\text { Will you have experience on taking decisive disciplinary } \\
\text { courses before? }\end{array}$} & Yes: 34 (36.17\%) & No: 60 (63.83\%) \\
\hline \multicolumn{3}{|c|}{$\begin{array}{l}\text { Will you have experience on taking multidisciplinary courses of } \\
\text { technological and decisive disciplinary before? }\end{array}$} & Yes: 14 (14.89\%) & No: $80(85.11 \%)$ \\
\hline \multicolumn{3}{|c|}{$\begin{array}{l}\text { Will you download the news, information and knowledge from } \\
\text { technological education websites? }\end{array}$} & Yes: 87 (9.25\%) & No: 7 (90.75\%) \\
\hline
\end{tabular}

Then, Table 3 described the evaluated measurements of the FA approach of quantitative analysis; the Kaiser-Meyer-Olkin measure of sampling adequacy of the random 84 senior higher education participators questionnaires was 0.806 (higher than 0.7) but the assessed number of significance of the Kaiser-Meyer-Olkin measure and Barlett test was 0.0000 ... . . . (lower than 0.05), which validated the accuracy of the appraised consequences.

Table 3. The Kaiser-Meyer-Olkin measure and Bartlett's test of FA approach.

\begin{tabular}{ccc}
\hline \multicolumn{2}{c}{ Kaiser-Meyer-Olkin Measure of Sampling Adequacy } & $\mathbf{0 . 8 0 6}$ \\
\hline \multirow{3}{*}{ Bartlett test of sphericity } & Chi-squared test & 361.865 \\
& df & 153 \\
& Sig. & 0.000 \\
\hline
\end{tabular}

Finally, the 11 appraised factors commonalities of the FA approach were measured as the BIU (0.808), ASU (0.752) and AU (0.702) of the TAM model, SBS (0.82), MCED (0.8), SPS (0.756), DDIP (0.748) and COA (0.703) of the RDMM model, as well as SE (0.808), SC (0.791) and SR (0.757) of SLT theory in Table 4, and inductively, these 11 appraised factors commonalities were higher than 0.7 , which means that these 11 assessed criteria were explained the interdependency with the research topic. On the other hand, the other 7 appraised factors' commonalities of the FA approach were calculated as the PEU (0.658), PU (0.624) and EV (0.531) of TAM, SPS (0.69) and ID (0.662) of the RDMM model, as well as the SO (0.684) and SR (0.641) of SLT theory in Table 4. Evidently, these 7 appraised factors' commonalities were lower than 0.7 , which means that these 7 assessed criteria explain interdependency with the research topic. As a result, the original 18 evaluation criteria were decreased to 11 core evaluated criteria, with higher research representativeness and validity. 
Table 4. The commonality of assessed criteria of FA approach.

\begin{tabular}{cc}
\hline Criteria & Extraction \\
\hline External variable (EV) & 0.531 \\
Perceived usefulness (PU) & 0.624 \\
Perceived ease of use (PEU) & 0.658 \\
Attitude towards using (AU) & 0.702 \\
Behavioral intention to use (BIU) & 0.808 \\
Actual system use (ASU) & 0.752 \\
Diagnose the issues or problems (DDIP) & 0.748 \\
Clarify the objectiveness to be achieved (COA) & 0.703 \\
Search for possible solutions (SPS) & 0.756 \\
Sompare Evaluate and Allocate Weights to Criteria of Each Solution (CEAWCES) & 0.69 \\
Select the best solutions (SBS) & 0.82 \\
Control and evaluate decision-making (MCED) & 0.662 \\
Self-proactive (SP) & 0.8 \\
Self-efficacy (SE) & 0.757 \\
Self-regulation (SR) & 0.808 \\
Self-organization (SO) & 0.641 \\
Self-control (SC) & 0.684 \\
\hline Extracted Method: principal component analysis & 0.791 \\
\hline
\end{tabular}

\subsection{EM Method of Qualitative Analysis}

After the implementation of FA approach of quantitative analysis, the connected dependences among each evaluated criterion were comprehensively measured by the first 20 professional experts' weight-questionnaires of the EM method of qualitative analysis. According to the equation of the EM method of qualitative analysis, Table 5 directly demonstrated the related factor-loading of these 8 assessed criteria of the FA approach of quantitative analysis, among the TAM technological model, RDMM decision-making model, and the SLT autonomy-learning model.

Table 5. The related factor-loading of the entropy method (EM) method.

\begin{tabular}{cccccccccc}
\hline \multicolumn{3}{c}{ Rational Decision-Making Model (RDMM) } & \multirow{2}{*}{$\begin{array}{c}\text { Social Learning } \\
\text { Theory (SLT) }\end{array}$} & \multicolumn{3}{c}{ TAM } \\
\hline SBS & MCED & SPS & DDIP & COA & & BIU & ASU & AU \\
\hline 0.2874 & 0.4112 & 0.2263 & 0.3814 & 0.2586 & SE & 0.3628 & 0.2754 & 0.1611 \\
0.1663 & 0.2874 & 0.1760 & 0.4858 & 0.2204 & SC & 0.2648 & 0.1041 & 0.1658 \\
0.0602 & 0.2204 & 0.1059 & 0.2874 & 0.2411 & SR & 0.0791 & 0.076 & 0.1822 \\
\hline
\end{tabular}

As a result of the assessed computations of the EM method, the related factor-loading were computed as BIU (0.3628) and ASU (0.2754) of TAM model and MCED (0.4112), SBS (0.2874), COA (0.2586) and SPS (0.2263), apparently influenced on the autonomy-learning performance in SE of SLT theory. Subsequently, the AU (0.1822) of TAM model directly impacted on the autonomy-learning performance in the SR of SLT theory, and the DDIP (0.4858) of the decision-making RDMM model affected the autonomy-learning performance in the SC of SLT theory.

\subsection{ANP Model of Quantitative Analysis}

Beyond the execution of the FA approach of quantitative analysis and the EM method of qualitative analysis, the effective TDDEEM model was synthetically constructed by means of computed consequences of the FA approach of quantitative analysis and the EM method of qualitative analysis, as shown in Figure 6. 


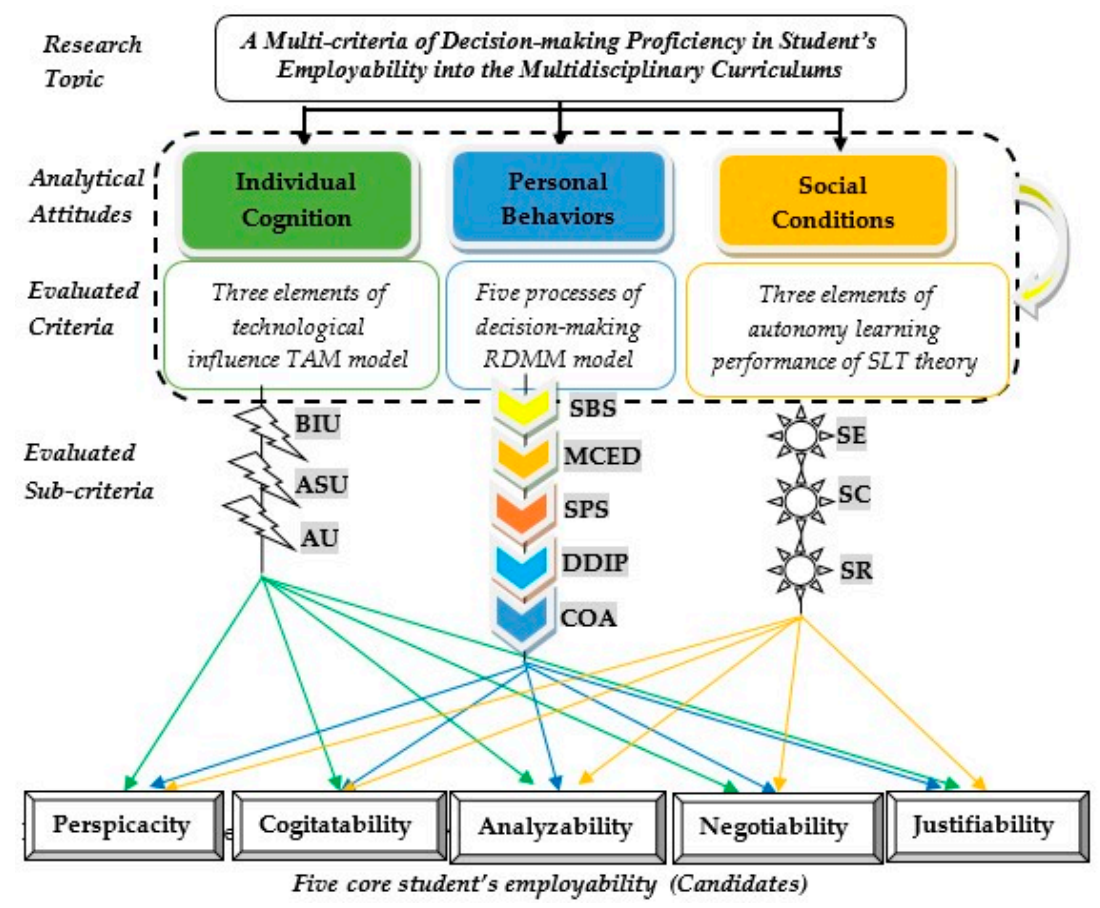

Figure 6. Research design empirical framework.

With reference to the C.I. and C.R. equations in each sub-criteria pairwise matrix, the entire consistencies of C.T. and C.R. (as described in Table 6) were lower than the low figure 0.1 that induced the 20 professional experts' weight questionnaires, and were suitable for the evaluated measurements of the ANP model of qualitative analysis, with higher research preciseness and veracity.

Table 6. The related factor-loading of ANP model.

\begin{tabular}{ccc}
\hline The Evaluated Criteria & C.I. & C.R. \\
\hline Individual Cognition & 0.0471 & 0.0812 \\
People Behaviors & 0.049 & 0.0845 \\
Social Condition & 0.0548 & 0.0945 \\
TAM & 0.0517 & 0.0892 \\
RDMM & 0.0578 & 0.0996 \\
SLT & 0.0502 & 0.0866 \\
BIU & 0.0727 & 0.0807 \\
ASU & 0.0591 & 0.0656 \\
AU & 0.0586 & 0.0651 \\
SBS & 0.0614 & 0.0651 \\
MCED & 0.0612 & 0.0679 \\
SPS & 0.0568 & 0.0631 \\
DDIP & 0.058 & 0.0645 \\
COA & 0.0546 & 0.0607 \\
SE & 0.0569 & 0.0632 \\
SC & 0.056 & 0.0623 \\
SR & 0.0568 & 0.0631 \\
\hline
\end{tabular}

Conclusively, as for considering the connections between each evaluated sub-criterion and research topic with higher research reliability, validity, representativeness and accuracy, the appraised commonalities of FA approach and the related factor-loading of EM method were both synthetically consolidated into the evaluated measurements of the ANP model in Table 7. As a result of Table 7, the standardized comparative evaluated indexes ("SCEN") of five evaluated candidates (perspicacity, cognitivity, analyzability, negotiability and judgeability) were hierarchically demonstrated and the highest SCEN was located at "Judgeability" (0.5071) and the three highest evaluated scales of sub-criteria were "self-efficacy (SE, 0.0884)", "self-control (SC, 0.0682)" and "self-regulation (SR, 0.0437)" in the ANP model, hierarchically. 
Table 7. The measured results of ANP model.

\begin{tabular}{|c|c|c|c|c|c|c|c|c|c|c|c|c|c|c|}
\hline \multirow[b]{2}{*}{ Criteria } & \multirow[b]{2}{*}{ Weights } & \multirow[b]{2}{*}{ FA-Commonality } & \multirow[b]{2}{*}{ EM-Factor-Loading } & \multirow[b]{2}{*}{ Sub-Criteria } & \multicolumn{2}{|c|}{ Perspicacity } & \multicolumn{2}{|c|}{ Cognitivity } & \multicolumn{2}{|c|}{ Analyzability } & \multicolumn{2}{|c|}{ Negotiability } & \multicolumn{2}{|c|}{ Judgeability } \\
\hline & & & & & Weights & $\begin{array}{l}\text { Evaluated } \\
\text { Score }\end{array}$ & Weights & $\begin{array}{l}\text { Evaluated } \\
\text { Score }\end{array}$ & Weights & $\begin{array}{l}\text { Evaluated } \\
\text { Score }\end{array}$ & Weights & $\begin{array}{c}\text { Evaluated } \\
\text { Score }\end{array}$ & Weights & $\begin{array}{c}\text { Evaluated } \\
\text { Score }\end{array}$ \\
\hline \multirow{3}{*}{ TAM } & \multirow{3}{*}{0.0608} & 0.808 & 0.3628 & BIU & 0.0331 & 0.0006 & 0.085 & 0.0015 & 0.1362 & 0.0024 & 0.2377 & 0.0042 & 0.5079 & 0.0091 \\
\hline & & 0.752 & 0.2754 & ASU & 0.0339 & 0.0004 & 0.084 & 0.0011 & 0.1364 & 0.0017 & 0.2368 & 0.003 & 0.5088 & 0.0064 \\
\hline & & 0.702 & 0.1822 & $\mathrm{AU}$ & 0.0336 & 0.0003 & 0.0834 & 0.0006 & 0.136 & 0.0011 & 0.2374 & 0.0018 & 0.5096 & 0.004 \\
\hline \multirow{5}{*}{ RDMM } & \multirow{5}{*}{0.2101} & 0.82 & 0.2874 & SBS & 0.0335 & 0.0017 & 0.0838 & 0.0041 & 0.1358 & 0.0067 & 0.2368 & 0.0117 & 0.51 & 0.0253 \\
\hline & & 0.8 & 0.4112 & MCED & 0.0329 & 0.0023 & 0.0833 & 0.0058 & 0.1352 & 0.0093 & 0.2376 & 0.0164 & 0.5109 & 0.0353 \\
\hline & & 0.756 & 0.2263 & SPS & 0.0324 & 0.0012 & 0.0824 & 0.003 & 0.1345 & 0.0048 & 0.2407 & 0.0087 & 0.5099 & 0.0183 \\
\hline & & 0.748 & 0.4858 & DDIP & 0.0329 & 0.0025 & 0.082 & 0.0063 & 0.1342 & 0.0102 & 0.2448 & 0.0187 & 0.5061 & 0.0386 \\
\hline & & 0.703 & 0.2586 & $\mathrm{COA}$ & 0.0329 & 0.0013 & 0.0822 & 0.0031 & 0.1328 & 0.0051 & 0.2447 & 0.0093 & 0.5073 & 0.0194 \\
\hline \multirow{3}{*}{ SLT } & \multirow{3}{*}{0.7303} & 0.808 & 0.2955 & SE & 0.0333 & 0.0058 & 0.0819 & 0.0143 & 0.1349 & 0.0235 & 0.2427 & 0.0423 & 0.5072 & 0.0884 \\
\hline & & 0.791 & 0.2338 & SC & 0.0333 & 0.0045 & 0.082 & 0.0111 & 0.1347 & 0.0182 & 0.2452 & 0.0331 & 0.5047 & 0.0682 \\
\hline & & 0.757 & 0.1565 & SR & 0.0334 & 0.0029 & 0.0821 & 0.0071 & 0.1349 & 0.0117 & 0.2447 & 0.0212 & 0.5049 & 0.0437 \\
\hline \multicolumn{4}{|c|}{ Synthetically comparative index numbers (SCIN) } & & & 0.0332 & & 0.0824 & & 0.1348 & & 0.2425 & & 0.5071 \\
\hline
\end{tabular}




\section{Research Conclusions and Recommendations}

Nowadays, many Taiwanese enterprises require decision-making employability (perspicacity, cognitivability, analyzability, negotiability and judgeability) as a main consideration and condition for recruiting higher education graduates. For this reason, this research not only comprehensively assays and analyzes the interdependence among the technological influence, learning performance and decision-making processes through the consolidation of technological TAM, self-learning STL theory and the decision-making RDMM model for academically resupplying the research gap and empirically providing the most effective course's strategy in developing a series of interdisciplinary curriculums to efficiently advance the higher education graduate's employment rate and effectively increase their student registration rate.

Significantly, in order to strengthen research reliability, validity, representativeness and accuracy, the FA approach of quantitative analysis was not only firstly employed to systematically identify the entire commonalities of each evaluated criterion, but the EM method of qualitative analysis was also secondly applied to comprehensively recognize the connected dependences among each evaluated criterion. In addition, the ANP model of qualitative analysis was further utilized to hieratically assess consistencies between each evaluated criterion for synthetically constructing the most effective TDDEEM model for discovering the multi-criteria of decision-making proficiency in a student's employability into the multidisciplinary curriculums.

Significantly, beyond a series of evaluated measurements of the FA approach of quantitative analysis and the EM method and ANP model of qualitative analysis in Table 7, there are four valuable and contributive findings, which are:

1. The "Judgeability" of decision-making employability was the most critical decision-making employability for corporate recruiting consideration and "Judgeability" was further directly influenced by the "SE, SC and SR" of autonomy-learning performance. Significantly, current higher education organizations have commenced their institution of the decisive "Judgeability" in the multidisciplinary curriculums, in order to nurture and develop student's "SE, SC and SR" decision-making capacity and proficiency in student's employability.

2. Precisely, "SE" of the autonomy-learning performance was directly influenced by the multi-criteria of "BIU and ASU" of TAM model and "MCED, SBS, COA and SPS" of the decision-making of RDMM model. This means that most companies request that the higher education graduates must possess the decisive "Judgeability" employability, to confidently deal with the diversified problem-solving issues by actually using various technological applications for clarifying, monitoring, controlling and evaluating the decision-making objectiveness, as well as systematically searching through all of the possible solutions in order to eventually induce the most suitable solutions for the diversified problem-solving issues.

3. Notably, "DDIP" of the decision-making RDMM model positively affected the "SC" of autonomy-learning performance, because most companies believe that higher education graduates are supposed to have the decisive "Judgeability" employability skill, to exercise the introspection capacity to thoroughly define and diagnose the diversified problem-solving issues through an interdisciplinary curriculum.

4. Particularly, the "AU" of the technological TAM model also obviously impacted the "SR" of autonomy-learning performance, because most companies demand higher education graduates who can assess, revise and justify their self-action capacity in thinking, motivation, feeling, cognition and have the behavior from the interdisciplinary curriculum instilled that allows them to cultivate their self-observing experience.

Ultimately, as for the research limitation, not only does the extension of quantitative and qualitative analysis methods and models of MCDM methodology need to be utilized in the relative research with technological influence, learning performance and decision-making processes research fields and the expansion of surveyed data need be considered in the future directions, beyond this research. 
Author Contributions: Writing—original draft, M.Y.H.; Writing—review and editing, Y.-M.H. and M.U. All authors have read and agreed to the published version of the manuscript.

Funding: This research was funded by research projects (MOST 108-2511-H-142-009 -; MOST 107-2420-H-002007-MY3-Y10909) of the Ministry of Science and Technology in Taiwan.

Conflicts of Interest: The authors declare no conflict of interest.

\section{References}

1. Chan, Y.K.; Hsieh, M.Y.; Lee, C.F.; Huang, C.C.; Ho, L.C. Inquiring the most critical teacher's technology education competences and in the highest efficient technology education learning organization. Eur. Math. Sci. Tech. Ed. 2017, 13, 2645-2664.

2. Huang, Y.-M.; Hsieh, M.-Y. An Interdisciplinary Research on Students' Employability in Technology Education to Advance Higher Education Enrollment Sustainability. Sustainability 2020, 12, 1806. [CrossRef]

3. Avramenko, A. Enhancing students' employability through business simulation. Educ. Train. 2012, 54, 355-367. [CrossRef]

4. Latham, J. A Framework for Leading the Transformation to Performance Excellence Part I: CEO Perspectives on Forces, Facilitators, and Strategic Leadership Systems. Qual. Manag. J. 2013, 20, 12-33. [CrossRef]

5. Hsieh, M.-Y. Online Learning Era: Exploring the Most Decisive Determinants of MOOCs in Taiwanese Higher Education. Eurasia J. Math. Sci. Technol. Educ. 2016, 12, 1163-1188. [CrossRef]

6. Hsieh, M.Y.; Chan, Y.K. Is online learning able to effectively decrease tuition and miscellaneous fees debt of higher education in Taiwan? Eurasia J. Math. Sci. Tech. Ed. 2016, 12, 1313-1326.

7. Hindess, B. Choice, Rationality and Social Theory; Unwin Hyman: London, UK, 1988.

8. Ford, C.; Goia, D. Factors influencing creativity in the domain of managerial decision making. J. Manag. 2000, 26, 705-732. [CrossRef]

9. Kaygin, B.; Budak, I. An Investigation of Mathematically Promising Students' Cognitive Abilities and Their Contributions to Learning Environment. Eurasia J. Math. Sci. Technol. Educ. 2015, 11, 25-36. [CrossRef]

10. Webb, T.; Sheeran, P. Can implementation intentions help to overcome ego-depletion? J. Exp. Soc. Psychol. 2003, 39, 279-286. [CrossRef]

11. Vohs, K.D.; Faber, R.J. Spent Resources: Self-Regulatory Resource Availability Affects Impulse Buying. J. Consum. Res. 2007, 33, 537-547. [CrossRef]

12. Vohs, K.D.; Heatherton, T.F. Self-regulatory failure: A resource-depletion approach. Psychol. Sci. 2000, 11, 249-254. [CrossRef]

13. Miller, N.E.; Dollard, J. Social Learning and Imitation; Yale Press: New Haven, CT, USA, 1941.

14. Bandura, A. Organizational Application of Social Cognitive Theory. Aust. J. Manag. 1988, 13, $275-302$. [CrossRef]

15. Baumeister, R.F. Yielding to Temptation: Self-Control Failure, Impulsive Purchasing, and Consumer Behavior. J. Consum. Res. 2002, 28, 670-676. [CrossRef]

16. Lorist, M.; Boksem, M.A.; Ridderinkhof, K.R. Impaired cognitive control and reduced cingulate activity during mental fatigue. Cogn. Brain Res. 2005, 24, 199-205. [CrossRef]

17. Hsieh, M.-Y. An Empirical Study of Education Divide Diminishment through Online Learning Courses. Eurasia J. Math. Sci. Technol. Educ. 2017, 13, 3189-3208. [CrossRef]

18. Hsieh, M.-Y. Exploring the Most Decisive Online Education Determinants as Impacted by Taiwan's New Southbound Policy. Eurasia J. Math. Sci. Technol. Educ. 2018, 14, 1945-1962. [CrossRef]

19. Vohs, K.D. Self-Regulatory Resources Power the Reflective System: Evidence From Five Domains. J. Consum. Psychol. 2006, 16, 217-223. [CrossRef]

20. Vohs, K.D.; Baumeister, R.F.; Ciarocco, N.J. Self-Regulation and Self-Presentation: Regulatory Resource Depletion Impairs Impression Management and Effortful Self-Presentation Depletes Regulatory Resources. J. Personal. Soc. Psychol. 2005, 88, 632-657. [CrossRef] [PubMed]

21. Muraven, M.; Tice, D.M.; Baumeister, R.F. Self-control as limited resource: regulatory depletion patterns. J. Personal. Soc. Psychol. 1998, 74, 774-789. [CrossRef]

22. Hsieh, M.-Y.; Usak, M. High Education Radical Transformation Era: How Teachers' Competency can enhance the Students' Employability? Rev. Cercet. Interv. Sociala 2020, 68, 95-112. [CrossRef] 
23. Hsieh, M.Y. Employing MCDM methodology to verify correlationship between social media and service quality in the dynamic m-commerce era. J. Internet. Tech. 2018, 19, 225-239.

24. Henseler, J.; Chin, W.W. A Comparison of Approaches for the Analysis of Interaction Effects Between Latent Variables Using Partial Least Squares Path Modeling. Struct. Equ. Model. Multidiscip. J. 2010, 17, 82-109. [CrossRef]

25. Baumeister, R.F.; Vohs, K.D.; Funder, D.C. Psychology as the Science of Self-Reports and Finger Movements: Whatever Happened to Actual Behavior? Perspect. Psychol. Sci. 2007, 2, 396-403. [CrossRef] [PubMed]

26. Vohs, K.D.; Heatherton, T.F. Self-esteem and threats to self: Implications for self-construals and interpersonal perceptions. J. Personal. Soc. Psychol. 2001, 81, 1103-1118. [CrossRef]

27. Wang, W.-M.; Peng, H.-H. A Fuzzy Multi-Criteria Evaluation Framework for Urban Sustainable Development. Mathematics 2020, 8, 330. [CrossRef]

28. Brikaa, M.G.; Zheng, Z.; Ammar, E.-S. Resolving Indeterminacy Approach to Solve Multi-Criteria Zero-Sum Matrix Games with Intuitionistic Fuzzy Goals. Mathematics 2020, 8, 305. [CrossRef]

29. Gailliot, M.T.; Baumeister, R.F. Self-Regulation and Sexual Restraint: Dispositionally and Temporarily Poor Self-Regulatory Abilities Contribute to Failures at Restraining Sexual Behavior. Personal. Soc. Psychol. Bull. 2007, 33, 173-186. [CrossRef] [PubMed]

30. Schwartz, B. Self-determination: The tyranny of freedom. Am. Psychol. 2000, 55, 79-88. [CrossRef]

31. Luce, M.F.; Payne, J.W.; Bettman, J.R. Emotional trade-off difficulty and choice. J. Mark. Res. 1999, 36, $143-159$. [CrossRef]

32. Khan, M.J.; Kumam, P.; Liu, P.; Kumam, P.; Ashraf, S. A Novel Approach to Generalized Intuitionistic Fuzzy Soft Sets and Its Application in Decision Support System. Mathematics 2019, 7, 742. [CrossRef]

33. Herbert, M. Models of Bounded Rationality, 1, Economic Analysis and Public Policy; MIT Press: Cambridge, MA, USA, 1982; pp. 235-244.

34. Shao, S.; Zhang, X. Measures of Probabilistic Neutrosophic Hesitant Fuzzy Sets and the Application in Reducing Unnecessary Evaluation Processes. Mathematics 2019, 7, 649. [CrossRef]

35. Hsieh, M.Y. An interdisciplinary experimental research on delving into the most potential AI technologies determinants in purchasing decision-making processes of IoT e-commerce. Appl. Sci. 2020, 10, 603. [CrossRef]

36. Bagozzi, R. University of Michigan The Legacy of the Technology Acceptance Model and a Proposal for a Paradigm Shift. J. Assoc. Inf. Syst. 2007, 8, 244-254. [CrossRef]

37. Chuttur, M.Y. Overview of the technology acceptance model: Origins, developments and future directions. Sprouts Work. Pap. Inf. Syst. 2009, 9, 1.

38. Cattell, R.B. Factor Analysis; Harper: New York, NY, USA, 1952.

39. Sahin, Z.; Yenmez, A.A.; Erbas, A.K. Relational Understanding of the Derivative Concept through Mathematical Modeling: A Case Study. Eurasia J. Math. Sci. Technol. Educ. 2015, 11, 177-188. [CrossRef]

40. Warne, R.T.; Larsen, R. Evaluating a proposed modification of the Guttman rule for determining the number of factors in an exploratory factor analysis. Psychol.Test Assess. Model. 2014, 56, 104-123.

41. Saaty, T.L. Decision Making with Dependence and Feedback: The Analytic Network Process; RWS Publications: Pittsburgh, PA, USA, 1996.

42. Saaty, T.L. Multi-Criteria Decision Making: The Analytic Hierarchy Process; RWS Publications: Pittsburgh, PA, USA, 1998.

(C) 2020 by the authors. Licensee MDPI, Basel, Switzerland. This article is an open access article distributed under the terms and conditions of the Creative Commons Attribution (CC BY) license (http://creativecommons.org/licenses/by/4.0/). 